\title{
ERRATUM
}

\section{Erratum to: Assessing the Total Mortality Caused by Two Species of Trichogramma on Its Natural Host Plutella xylostella (L.) at Different Temperatures}

\author{
CA Marchioro ${ }^{1}$, FS KreChemer ${ }^{2}$, LA Foerster ${ }^{2}$ \\ ${ }^{1}$ Univ Federal de Santa Catarina, Curitibanos, SC, Brasil \\ ${ }^{2}$ Depto de Zoologia, Univ Federal do Paraná, Curitiba, PR, Brasil
}

\section{Erratum to: Neotrop Entomol}

\section{DOI 10.1007/s13744-014-0263-4}

Due to an unfortunate turn of events, an error was introduced in the caption of the $y$-axis of Fig 2. The correct image and its caption are published here and should be treated as definitive by the reader.
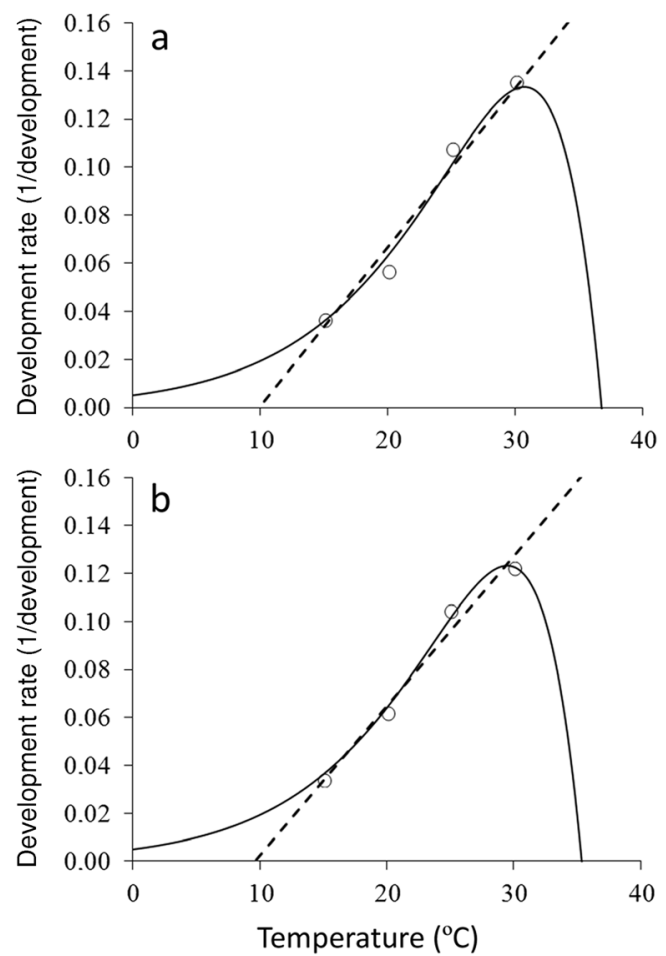

Fig 2 Curve fitting of the linear model (dashed line) and the nonlinear model (solid line) was used to describe the relationship between temperature and development rate of Trichogramma pretiosum (a) and Trichogramma atopovirilia (b) on eggs of Plutella xylostella. Empty circles are observed values. 